\title{
Regulatory T cells affect early relapse following high-dose chemotherapy with autologous hematopoietic stem cell trans- plantation in multiple myeloma patients
}

Egor V. Batorov, Marina A. Tikhonova, Irina V. Kryuchkova, Vera V. Sergeevicheva, Svetlana A. Sizikova, Galina Ju. Ushakova, Dariya S. Batorova, Andrey V. Gilevich, Ekaterina Y. Shevela, Elena R. Chernykh

Research Institute of Fundamental and Clinical Immunology, Novosibirsk, Russia

Contact: Dr.Egor V. Batorov, Research Institute of Fundamental and Clinical Immunology, Novosibirsk, Russia

E-mail: Ebatorov@gmail.com

\section{Introduction}

Regulatory T cells (Tregs) play an important role in pathogenesis of multiple myeloma (MM), providing tumor cell avoidance of immune surveillance. The latter, in turn, are able to induce the Treg expansion. However the data on their contents at different stages of disease and their relations to efficiency of the therapy performed are incomplete and controversial. The aim of this study was to investigate dynamics of CD4+FOXP3+ regulatory T cells (Treg) recovery following high-dose chemotherapy (HDCT) with autologous hematopoietic stem cell transplantation (AHSCT), and possible relationship between Tregs and clinical outcomes in multiple myeloma (MM) patients.

\section{Patients and methods}

Fifty-nine patients with MM (median age 49 years, range 32-64) underwent AHSCT in 2009-2015. For stem cell mobilization, patients were administered high-dose cyclophosphamide $(4 \mathrm{~g} / \mathrm{m} 2)$ or another standard chemotherapy course + G-CSF, melfalan 140-200 mg/m was used as conditioning regimen. The average CD34+ hematopoietic stem cell dose was $5.9 \pm 2.7 \times 10^{6} / \mathrm{kg}$ (here and below data as $\mathrm{M} \pm \mathrm{SD}$ ). The median observation time was 21 month. The counts of circulating CD4+FOXP3+ Tregs have been evaluated using flow cytometry (BD FACSCalibur, CellQuest Software) before HDCT with AHSCT at the day of engraftment, and following 6 and 12 months. The Mann-Whitney U test was used to calculate differences between groups of patients. ROC-analysis with area under the curve calculation was used to evaluate the predictive value. $\mathrm{P}<0.05$ was considered statistically significant confidence level.

\section{Results}

Pre-transplant count of CD4+FOXP3+ Tregs was 4.0 $43.0 \%$. Percentage of Tregs restored rapidly, became higher than initial pre-transplant level $(5.5 \pm 3.3 \%$; $\mathrm{pU}=0.028)$ at the time of engraftment ( $\sim$ the 14th day following AHSCT) and then subsequently decreased for a year until it lowered to $2.3 \pm 1.3$ $\%$. CD4+FOXP3+ Tregs at the time of engraftment were increased in patients with relapse of disease during 12 months following AHSCT $(n=7)$ compared to non-relapsed patients $(\mathrm{n}=29): 7.9 \pm 2.6$ vs $4.6 \pm 2.5 \%$; $\mathrm{pU}=0.0066$. The prognostic value of CD4+FOXP3+ Treg relative counts at the day of engraftment was assessed for relapse rates at the 1st year post-transplant. Area under the curve (AUC) was 0.835 (95 \% CI: 0.678-0.992; $\mathrm{p}=0.0066)$. CD4+FOXP3+ Treg relative count $>5.77 \%$ allowed to predict early relapse $(85.7 \%$ sensitivity, $75.7 \%$ specificity, with 3.55 likelihood ratio).

\section{Conclusions}

Relative counts of Tregs recovered rapidly following HDCT with AHSCT (at the day of engraftment), became higher than pre-transplant level and then subsequently decreased within a year to healthy donor values. The excess of Tregs at the time of engraftment is associated with early relapse.

\section{Keywords}

Multiple myeloma, autologous hematopoietic stem cell transplantation, regulatory $\mathrm{T}$ cells, early relapse. 


\section{Роль регуляторных Т-клеток в развитии раннего рецидива после высокодозной химиотерапии с аутологичной трансплантацией гемопоэтических стволовых клеток у больных множественной миеломой}

Егор В. Баторов, Марина А. Тихонова, Ирина В. Крючкова, Вера В. Сергеевичева, Светлана А. Сизикова, Галина Ю. Ушакова, Дарья С. Баторова, Андрей В. Гилевич, Екатерина Я. Шевела, Елена Р. Черных

Научно-исследовательский институт фундаментальной и клинической иммунологии, г. Новосибирск, Россия

\section{Введение}

Регуляторные Т-клетки (Трег) играют важную роль в патогенезе множественной миеломы (МM), обеспечивая уход опухолевых клеток из-под иммунного надзора, которые, в свою очередь, способны индуцировать экспансию Трег. Однако данные об их содержании при различных фазах болезни и связи с эффективностью проводимой терапии неполны и противоречивы. Цель работы состояла в изучении динамики восстановления Трег у больных ММ в условиях истощения опухолевого клона и длительной лимфопении после высокодозной химиотерапии (ВДХТ) c аутологичной трансплантацией гемопоэтичекских стволовых клеток (АТГСК) и взаимосвязь между количеством Трег и течением посттрансплантационного периода.

\section{Пациенты и методы}

В исследование были включены 59 больных ММ, которым была проведена ВДХТ с АТГСК в 2009-2015 гг. Медиана возраста - 49 лет (32-64 года). Режим мобилизации - высокодозный циклофосфамид (4г/м2), либо курс стандартной химиотерапии и препарат Г-КСФ, режим кондиционирования - мелфалан 140-200 мг/м². Доза CD34+ гемопоэтических стволовых клеток - 5,9 $\pm 2,7 \times 10^{6} /$ кг (здесь и далее данные в виде $\mathrm{M} \pm \mathrm{SD})$. Медиана наблюдения - 21 месяц. Количество циркулирующих CD4+FOXP3+ Трег оценивали методом проточной цитометрии (BD FACSCalibur, CellQuest Software) перед ВДХТ, в день выхода из лейкопении, через 6 и 12 месяцев после АТГСК. Для оценки значимости различий между группами больных использовали $\mathrm{U}$-критерий Манна-Уитни. Для оценки диагностической значимости использовали ROC-анализ с расчетом площади под кривой. Различия считали достоверными при уровне значимости $\mathrm{p}<0,05$.

\section{Результаты}

Перед ВДХТ с АТГСК относительное количество CD4+FOXP3+ Трег составило 4,0 $\pm 3,0 \%$. В отличие от других субпопуляций Т-лимфоцитов, относительное содержание Трег восстанавливалось уже ко времени выхода из лейкопении (в среднем, 14-й день после АТГСК) и было значимо выше предтрансплантационных значений $(5,5 \pm 3,3 \%$; $\mathrm{pU}=0,028)$, с дальнейшим снижением в течение года до $2,3 \pm 1,3 \%$.

Анализ исходов АТГСК в группе 36 пациентов показал, что рецидив или прогрессия ММ в течение первого года после ТГСК наблюдалась у семи больных. У этих пациентов относительное содержание CD4+FOXP3+ Трег на день выхода из лейкопении было более высоким по сравнению с пациентами, сохранившими ремиссию $\mathrm{MM}(\mathrm{n}=29):$ 7,9 $\pm 2,6 \%$ против $4,6 \pm 2,5 \%$; pU=0,0066. Относительное содержание Трег на других контрольных точках не отличалось у больных с ранним рецидивом и в ремиссии заболевания. Для определения прогностической значимости содержания Трег на момент восстановления лейкоцитов в прогнозе раннего исхода ТГСК был проведен ROC-анализ. Построение ROC-кривой выявило высокую информативность определения содержания Трег. Площадь под кривой относительного количества CD4+FOXP3+ Т-клеток в прогнозе развития рецидива в течение 12 мес. после АТГСК составила 0,835 (95 \% ДИ: 0,678-0,992; p=0,0066). Относительное содержание CD4+FOXP3+ Т-клеток более 5,77 \% позволяло прогнозировать неблагоприятный исход с чувствительностью 85,7 \% и специфичностью 75,7\%, отношение правдоподобия 3,55.

\section{Заключение}

Относительное содержание Трег у больных ММ после ВДХТ с АТГСК быстро (ко времени выхода из лейкопении) достигает и превышает предтрансплантационный уровень, после чего снижается и к исходу 12 мес. достигает нормативных значений. Развитие раннего рецидива заболевания после АТГСК ассоциируется с более высоким содержанием Трег ко времени выхода из лейкопении; оценка относительного содержания этих клеток по предварительным данным может быть использована для прогнозирования течения посттрансплантационного периода.

\section{Ключевые слова}

Множественная миелома, аутологичная трансплантация гемопоэтических стволовых клеток, регуляторные Т-клетки, ранний рецидив. 